\title{
Instrumentos para la política cultural y el desarrollo sostenible: el IAPH y otros centros de patrimonio en España
}

\author{
Javier Rivera Blanco \\ Catedrático de Historia de la Restauración. \\ Director del Instituto Español de Arquitectura \\ Universidad de Valladolid
}

Muchas gracias al Director del IAPH, D. Román Fernández-Baca, muchas gracias a todos los organizadores de este acto que nos reúne aquí para conmemorar los diez años de la fundación del Instituto Andaluz de Patrimonio Histórico, y sobre todo, gracias a todos los presentes porque nos une una preocupación, la de articular lo mejor posible la tutela de nuestra herencia cultural y plantearnos el futuro de estas instituciones.

Yo no sé si Román me invita por ser director del Instituto Español de Arquitectura de la Universidad de Valladolid, que por su apellido geográfico parece reflejar algo importante, grande, una organización de escala nacional o española. Pues bien, el I.E.A., mi instituto, es una entelequia, es una utopía. Se trata de una pequeña organización, a pesar del nombre, que nace del acuerdo de colaboración suscrito en 1996 por los respectivos rectores de las universidades de Alcalá y Valladolid D. Manuel Gala y D. Fernando Tejerina. Les sonaban mal otros nombres que pudieran acoger sentidos y significaciones comunes o referencias abstractas, como aquellas de Instituto madrileño- vallisoletano u otras cosas parecidas, por lo que lo más fácil fue llamarlo español de arquitectura por su dedicación a este campo específico.

Mi instituto cuenta con una financiación de la universidad de 207.300 pesetas al año (ejercicio del año 1999), y con el soporte logístico de un pequeño local -un sótano en la Escuela de Arquitectura-, a lo que hay que sumar la luz y la calefacción. Todo lo demás corre por cuenta del Instituto que autofinancia todas sus actividades. Con ello se lo explico todo, desde los investigadores y los becarios, los sellos, el teléfono, las mesas, ordenadores, gestión, viajes, secretaría, dirección, etc. Uno de los mayores males de la universidad pública española, es que sus profesores deben ser en primer lugar buenos docentes (porque en caso contrario no transfieren conocimientos y, además, no se les conceden los complementos de los quinquenios para ampliar miserablemente el sueldo), luego deben ser buenos investigadores (porque si no su "currículo" queda anticuado con rapidez y porque de no ser

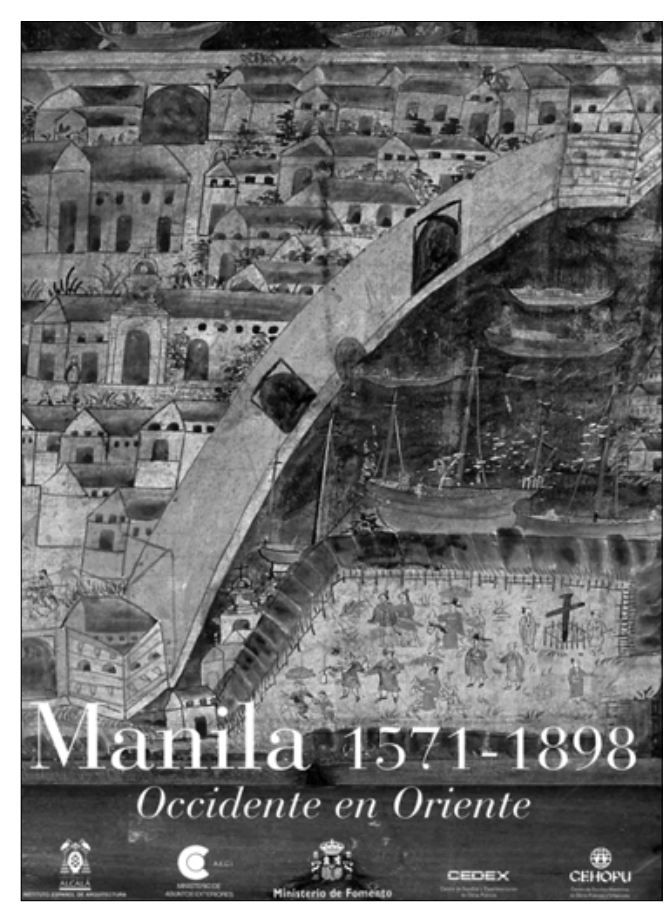

competitivo no se les conceden los sexenios con su implicación en la economía personal y en el desprestigio profesional), después tienen que ser hábiles burócratas (para presentarse a becas y proyectos, para responder a la "fiebre de papeleo" que ahoga a las universidades y a las administraciones); no acaba aquí la cosa y finalmente deben ser activos y "águilas" gestores (para conseguir proyectos, encargos, para relacionarse con la sociedad, con otros países y universidades, etc.) y todo a cuenta del tesoro personal, o del Instituto universitario en este caso. A pesar de todo ello, en el mismo ejercicio en que recibimos de la Universidad de Valladolid la cantidad mencionada, entraron en sus arcas más de sesenta millones de pesetas brutas de los proyectos que gestionamos (programas europeos, proyectos, congresos, diseños, Feria Nacional de la Restauración AR\&PA, investigaciones para varios ministerios, planes directores, etc.).

\section{Los nuevos retos del patrimonio: ¿hacia dónde van los institutos?}

Para mí es muy importante estar aquí, en este simposio, pues he de reconocer públicamente -ya lo he hecho otras muchas veces- que tengo una profunda y sana envidia porque en mi tierra hubiera un ente 
como el Instituto Andaluz de Patrimonio Histórico. Con ello les expreso mi admiración por lo que ha realizado y representa esta organización.

Todos los que hemos dedicado buena parte de nuestra vida a trabajar en y con el Patrimonio tratamos de comprender, de interpretar, lo que está ocurriendo en este universo tan complejo, y qué es lo que le espera en un futuro inmediato. Es cierto que estamos observando una transformación importante y radical en su definición y conceptos; estamos siendo testigos de una evolución extraordinaria de su significación en la sociedad. Y dentro de este proceso se está produciendo igualmente una conciencia distinta respecto de aquellos objetos e ideas que hasta ahora clasificábamos como sujetos del Patrimonio, aquellos que habíamos regulado, o sobre los que nos habíamos concienciado, para crear una responsabilidad moral y jurídica capaz de recibirlos y obligada a trasmitirlos a quienes vinieren detrás de nosotros, para que ellos también tengan la posibilidad de disfrutarlos o de utilizarlos.

Este planteamiento nos llevaría a introducirnos, si dispusiéramos del tiempo y el espacio preciso, en esas transformaciones del concepto de Patrimonio del que hablamos, lo que nos conduce también hacia el debate que aquí nos reúne. En efecto, el presente y el futuro de los Institutos o Centros dedicados al Patrimonio, y específicamente del IAPH, se relaciona con la necesidad de su existencia y los objetivos de su desarrollo temporal y espacial; problema que afecta al resto de instituciones y organizaciones similares que tienen "aparentemente" idénticos fines.

¿Qué problemas platea en la actualidad el Patrimonio? Cuando leemos el Boletín de Patrimonio Histórico del IAPH u otras revistas internacionales de carácter similar, muchos de sus artículos indagan en la definición de qué es lo que hay que clasificar, qué es lo nuevo que se presenta con sus valores, qué nuevas condiciones aparecen según la cultura actual y todo aspirando a que se conviertan en un elemento fundamental del desarrollo sostenible de quien los posee. Es, pues, un problema ya epistemológico. No nos valen las clasificaciones tradicionales de las Cartas de la Restauración sagradas (Atenas, Venecia, Amsterdam, Nairobi, Florencia, etc., etc.). La más reciente de Cracovia (2000) habla ya por primera vez de que el Patrimonio lo identifica cada colectividad, en la mayoría de los casos al margen de las restantes. Son cada una de ellas quienes encuentran los valores colectivos que las identifican en determinados elementos del pasado que pueden carecer de valor para otras culturas. Y no estamos hablando sólo de la diferencia Oriente-Occidente, Europa- África y el resto, sino de cambios estructurales dentro de los mismos países o unidades culturales. También menciona este reciente documento que hay que respetar en los monumentos y conjuntos incluso factores que hoy no nos son permitido comprenderlos. iEsto es "ultraconservacionismo?". O como se expresó en las reuniones preparatorias y en la final ies consciencia de la complejidad por la que va avanzar en los próximos tiempos el Patrimonio?
Personalmente, como no estoy vinculado al IAPH en intereses de ninguna clase, puedo tratar de hacer una valoración de su trabajo, leal y siempre en la medida de mis conocimientos y de los datos que poseo, pues desde la distancia no se está mediatizado por factores personales o locales, aunque, cierto, también se carecen de más completos parámetros de incidencia.

El Consejero de Cultura de la Junta de Andalucía que ha iniciado estas jornadas nos hablaba de cómo se fue gestando la idea de crear este Instituto por aquellos años difíciles, los de los 82, 83, 84 y en adelante hasta el 89 en el que por fin se publica el decreto de fundación. Años en los que se transfieren a la Comunidad de Andalucía las competencias en Patrimonio, en los que las Autonomías eran poco comprendidas por los propios administrados, como provocaban cierta abulia -por usar una palabra más o menos no agresiva- y como tenían que competir como administraciones periféricas con ese Estado tradicional que agonizaba, el Estado centralista. Todo dentro de la necesidad de la discusión entre el instrumento o la función. Qué primero: se tenía un patrimonio y una responsabilidad, pero se ignoraba cómo afrontarla; había que crear la conciencia de poseer unos valores del pasado importantes, pero no se sabía cómo o cuáles..., y además cómo concienciar, cómo conservar y restaurar, cómo transferir y qué y para qué y para quiénes.

El caso del IAPH es excepcional en España y no voy hablar mucho del IAPH puesto que se hará en los días próximos, pero es la envidia de todas las Regiones/Comunidades. En muchas de ellas han nacido centros de restauración o institutos de investigación y de conservación. Así, de restauración y de formación en este ámbito lo tienen Galicia, Castilla y León, Cataluña, etc. Y el modelo de instituto aparece en algunas leyes regionales como la de las Comunidades de Madrid, Galicia, Castilla y León -ésta aún en anteproyecto-y otras. El ejemplo a imitar originario fue el ICROA (Instituto Central de Restauración de Obras de Arte), ahora llamado Instituto de Patrimonio Histórico Español (I.P.H.E.), que a su vez se inspiró en el Instituto Centrale per il Restauro (I.C.R.) que fundara Cesare Brandi en Roma en el año de 1939.

Permítanme una falta de humildad para recordar que hace unos meses nos concedieron al IEA de la Universidad de Valladolid un programa de investigación "Rafael" (Unión Europea, Dirección General X), para trabajar sobre "Criterios de Restauración en la Nueva Europa" con las universidades de Cracovia, Budapest, Gante, Venecia y Praga, saliendo victoriosos de entre las tres mil y pico solicitudes de Europa. Al revisar las concesiones efectuadas a todos los aspirantes del continente en España solo aparecía el IAPH y nosotros, los andaluces, nada más ni nada menos que con tres programas concedidos para investigar con otros grupos europeos. Esto, evidentemente, era un orgullo para cualquier español, era un reconocimiento internacional para cualquier persona que investigaba en estos temas y que se preocupaba por ellos y 


\author{
Los Institutos de Patrimonio, y en este caso querría señalar \\ alguna objeción a los planteamientos actuales de muchos de \\ ellos, no deben ser meras oficinas de burocracia informativa o \\ simples talleres de ejecución de algunas actividades, deben ser \\ creadores de nuevas capacidades de gestión y de intervención.
}

\begin{abstract}
a la vez nos llamaba la atención el hecho de que otras instituciones españolas, otros centros desde hace décadas dedicadas a ello, no estuvieran en ese ámbito de la búsqueda de medios, de fuentes, de recursos del exterior para invertirlos en nuestros territorios y si lo estaban no hubiera sido aceptada su postulación. Por ejemplo, uno de los proyectos aprobados era sobre investigación en "escultura de madera policromada", un tema en el que ya el IAPH se había convertido en puntero en toda Europa.
\end{abstract}

Quiero con esto plantear en determinado grado, algunas de las dudas o los problemas que han surgido en estos últimos años. Si el concepto de Patrimonio, como decía Andrè Malraux, ha conocido una transformación violenta avanzado el siglo XX, hasta el grado de establecer un masivo encuentro, por parte de la sociedad, con la nueva idea de belleza que ha provocado la transgresión de todas las ideas elitistas que sobre ella se tenían durante el siglo XIX y buena parte del $X X$. En efecto, cuando miles de personas se agolpan a las puertas de los museos, a las puertas de las exposiciones, a las puertas de los monumentos de toda Europa y de muchos de otros países de Oriente y de Occidente, esto es reflejo de una transformación profunda en la percepción y en la sensibilidad de los seres humanos, que antes sólo afectaba a los entendidos - los expertos- y que ahora se ha colectivizado y apunta a que en el siglo XXI se multiplique aún más.

¿Qué va ha ocurrir en este nuevo siglo? Quizá, demorando un poco la contestación, sí nos interesa situarnos en el estado actual de la definición de Patrimonio en nuestro ámbito, en el ámbito al menos Occidental. Los documentos vigentes, que plantean soluciones al respecto, -junto a las leyes localesson la Carta de Venecia, del año de 1964, y otras recomendaciones ya más específicas relativas a temas concretos, como la Carta de Florencia de Parques y Jardines, los documentos de ICOMOS (International Council on Monuments and Sites), y así sucesivamente otras, como las de urbanismo de Nairobi o Granada, las del Consejo de Europa, especialmente la de Amsterdam de 1975, también co- nocida como "Carta Europea de la Restauración", las Declaraciones de Patrimonio de la Humanidad por la UNESCO, etcétera, etcétera.

Son documentos que avanzan rápidamente sobre el proceso de recuperación de nuevos significados del pasado. Que afianzan los conceptos tradicionales de los sujetos del patrimonio y que van incluyendo las novedades del pensamiento contemporáneo, así como los resultados de las reflexiones actuales sobre la necesidad de la búsqueda de una identidad e individualización de los pueblos ante la amenaza -ya real- de la globalización que pretende uniformarnos a todos, en lo económico primero, en lo social y cultural después.

Haciendo un inciso, recordaré que me he llevado una desagradable sorpresa hace dos días, cuando viniendo a Sevilla leí en la prensa una declaraciones del director del Museo del Prado, que defendía públicamente, en relación con la famosa disputa sobre la ampliación de este edificio y el claustro de los jerónimos, que despreciaba la opinión de los vecinos del barrio del Museo, que como ustedes saben se han opuesto a estas obras alegando que crearán un entorno más problemático y disfunciones en el área, además de estar en contra de alterar el status quo. El responsable de la pinacoteca alegaba para justificar su postura que el Museo es patrimonio universal, que el Museo es de Velázquez y de Rubens, es de los japoneses y de los ecuatorianos, y que los vecinos del Salón del Prado nada tenían que decir al respecto, pues su posición era egoísta y no pensaba en los demás. Estando completamente de acuerdo con esto (¿quién va a discutir que Venecia es de todos y así sucesivamente?), no es menos cierto que los monumentos son antes que de nadie de quien convive cotidianamente con ellos y sin la "gente" que vive en su entorno, en su ambiente, todo proyecto de revitalización, transformación, uso, etc., está condenado al fracaso. Mientras no se cuente con ellos y se les explique qué proyectos se pretenden aplicar se comete un atropello, además de antidemocrático, contrario al pueblo que ha creado y da- 
do sentido precisamente a ese patrimonio, bien sea directa o indirectamente.

Desde este punto de vista algo se revela dentro de nosotros, pues el Patrimonio es la herencia de los padres; no es legítimo, ni lícito, extraer su propiedad y las responsabilidades que le acontecen de aquellas personas que conviven día a día con él. Por supuesto que es de los japoneses, de los ecuatorianos, que es un valor y una propiedad universales, pero antes que a todos estos, o por lo menos tanto, pertenece a aquellos que lo han heredado directamente, que trabajan a su lado, que son quienes lo comprenden, se benefician y sufren de su existencia. Las autoridades, los políticos y gestores, incluso los expertos, alegan muchas veces que al "vulgo" hay que orientarle, como si aún estuviéramos en el Despotismo llustrado. Esto no es cierto, a los ciudadanos hay que educarles en las diferentes fases de su formación y de su vida, y no necesitan a los demás para que decidan por ellos, precisamente ellos son los que les eligen para que cumplan sus mandatos, y uno de ellos es preservary acrecentar el patrimonio. Por esta razón también, dentro del cuerpo de los ciudadanos se desarrolla un sector de técnicos, que son quienes conocen los métodos, las técnicas y los criterios y en quien unos y otros delegan cuando cumplen su función a satisfacción de todos. Es aquí donde nace el IAPH, una parte del cuerpo de la sociedad para encargarse de esta labor, y con otra misión más encomendada, de gran trascendencia, indagar en los nuevos conceptos de patrimonio, descubrir nuevos caminos de la ciencia para protegerlos, abrir campos más extensos de concienciación, mejorar al máximo la capacidad de sus profesionales para adelantarse a los retos que se vienen encima. Y esta labor la está cumpliendo en Andalucía esta institución que es ejemplar y modélica para todas las del resto de España y de otros lugares de Europa, América y África. Tanto que adquiere cada día un protagonismo más elevado, aval y garantía de su producción y de sus positivos resultados.

El IAPH se inserta en estos nuevos rumbos que estamos apuntando. En la Carta de Cracovia 2000 que antes mencionábamos se ha tratado de responder a los nuevos planteamientos del Patrimonio en su ámbito construido y en relación con un mundo cambiante del que somos agentes y testigos. Las Cartas de Venecia (1964) o de Amsterdam (1975), por citar sólo dos de las más importantes, están en muchos de sus presupuestos muy lejanas de la situación contemporánea. Entonces Europa era colonialista y veía al mundo entero bajo sus únicos ojos. En estas últimas décadas han variado el Derecho Internacional y la jurisprudencia local, se han producido extraordinarios avances tecnológicos, se han descubierto muchos y muy diversos valores culturales hasta ahora despreciados. Ya no es, ni mucho menos, la Europa de Malraux -incluso a este personaje la nueva historiografía ya no lo presenta como un innovador en patrimonio, sino como depredador-, la Europa de hoy, por citar a otro pensador francés, es la de Raymond Aron, es la Europa de las regiones y de los pueblos que la integran, es la Europa que aspira a lu- char contra esa globalidad defendiendo las individualidades de los territorios. Pero además, es otra Europa multicultural y multiétnica, con migraciones entre sus propios países, del norte al Mediterráneo, del Este al Occidente, y de importantes inmigraciones extracontinentales también. Fenómenos todos que están influyendo fuertemente en la idea de belleza y en la idea de patrimonio por valorar y por conservar.

La renovación alcanza a elementos intangibles y espirituales. Así, recientemente se declaró Itinerario Cultural Europeo al Camino de Santiago, no por sus objetos o monumentos, ciudades, puentes, etc., sino por el discurso ideológico que representa de intercambio de culturas, por el transcurso de las personas, las idas y venidas entre Europa y Santiago de Compostela e igual va a ocurrir con el Camino de la Lengua Española. Se van a declarar las Rutas del Sahel, o los caminos de las Misiones jesuíticas que enlazaban a través del Amazonas espacios de Colombia y de Paraguay, por todo el cono sur americano. Los itinerarios de Al-Andalus también se han apreciado desde sus significados simbólicos y culturales. Es decir, se están redescubriendo valores inmateriales, significados que ya no expresan en soportes físicos, pero que de igual manera pertenecen a los conceptos de la memoria a rescatar y transmitir. Todo ello está ampliando la fenomenología del patrimonio. No se trata ya sólo de aquellos objetos medievales, que se valoraban en el siglo XIX, no son ya sólo aquellas ciudades históricas con sus tramas urbanas y sus hitos tradiciones dentro de aquella ya antigua visión del ambiente y el entorno que declaró la Carta de Atenas, no son sólo tampoco las arquitecturas rurales, aquellas llamadas en la de Atenas y Venecia "arquitecturas menores". También se ha asumido ampliamente -no todo lo que se debiera, también es cierto-, aquellas otras casuísticas introducidas en los años sesenta desde el mundo anglosajón o el francés, como las declaraciones de André Malraux, y otros políticos europeos, que incluyeron la declaración de las obras maestras de la arquitectura Racionalista del Movimiento Moderno y de la arqueología industrial. En esos años, 60, 64 y 65 se salva de la destrucción obras de Le Corbusier, como la Villa Saboya, la ermita de Nuestra Señora de Ronchamp, se considera monumento el convento de La Tourette, se salva de la demolición la biblioteca de Labrouste, y otros muchos ejemplos, tanto racionalistas como de arquitectura de hierro. De esta forma se introducen nuevos ámbitos en la consideración de patrimonio colectivo.

Otra innovación se ha verificado en los años 70 y 80, en los que se están introduciendo, también en el ámbito de las declaraciones, objetos de la ciencia y de la técnica, por ejemplo los carros de combate "Tigres" de la Primera Guerra Mundial, o el acelerador de iones de mediados de los 65 construido en Francia. En España se han clasificado igualmente locomotoras del ferrocarril (Mikado), edificios, construcciones preindustriales, etc. Objetos visibles, tangibles, materiales y en el nuevo ámbito se declaran factores espirituales, como costumbres, folklore, lenguas, hasta lugares de la memoria, donde no hay nada, sólo la referencia a 
un espacio que recuerda algo que existió alguna vez en el sitio. Ahora mismo aspira al reconocimiento de Patrimonio de la Humanidad, por ejemplo, la obra popular teatral conocida como el Misterio de Elche, los espacios vacíos de los mercados en las afueras de algunas ciudades musulmanas, las fiestas de Nairobi y otros aspectos más.

\section{EI IAPH en un universo nuevo del patrimonio}

¿Cuál es el papel de un Centro o de un Instituto de Patrimonio en nuestros días? $\bigcirc$ ¿cuál es el papel que debe desarrollar una institución en este sentido?

Habría que distinguir primero qué modelos existen en el mundo occidental, el que conocemos en alguna medida al respecto. Hay centros oficiales internacionales de carácter público, otros nacionales o internacionales son privados. Todos dependen de los presupuestos con que cuentan o de la posibilidad de generar convenios o ayudas de entidades públicas o privadas. Todos, a una escala o a otra, persiguen los mismos objetivos.

Los centros públicos pueden ser intergubernamentales, como el ICCROM (Centro Internacional de Estudios para la Conservación y la Restauración de los Bienes Culturales) que actúa y depende de los 97 estados miembros. El IPHE del Estado español o el ICR del Estado italiano. El IAPH como ejemplo de una comunidad, la de Andalucía, o el Centro de Restauración de Castilla y León. Estos ejemplos dependen de las autoridades respectivas que eligen sus líneas directrices de acción y aportan los medios para cumplir sus funciones.

El ICOMOS, ya mencionado, no es gubernamental e interviene en todo el planeta asesorando a la UNESCO en materia de patrimonio; se financia a través de las aportaciones de los miembros y de la ayuda de los países en los que está instaurado.

Como centros privados pueden citarse el Getty Conservation Institute que trabaja también en un amplio espectro internacional, y más cercanos Hispania Nostra, ARCHIVAL de Valencia, los Amigos del Serrablo, la Fundación Santa María de Aguilar o la del mismo nombre de Albarracín y otros muchos con dedicación más local y concreta y con medios relativos, aunque con labores excelentes.

Las universidades, o ligadas a ellas de alguna manera, también han amparado algunos centros de esta índole, como el Instituto Español de Arquitectura de las Universidades de Valladolid y Alcalá, con dos sedes independientes y autónomas, la de Alcalá, con muchos más medios. Vinculada a la Complutense existe la Asociación de Gestores de Patrimonio, que está rebasando nuestro ámbito geográfico y desplegándose por América. Otras más también merecen citarse, pero ni disponemos del espacio ni ese es el objetivo que perseguimos. Las entidades españolas todas son del período democrático, es decir, creadas después de 1975, lo que ya indica cuando ha surgido y cuando se ha desarrollado esta conciencia social de gran repercusión en la cultura material de los españoles.

La transición democrática española fue dura en lo que se refiere a la reivindicación de la tutela del patrimonio. Los años finales de los setenta y los ochenta, presentaron en carne abierta inmensos problemas de nuestro legado histórico. Después de una recuperación de la conciencia histórica, quizá muy ambiciosa en algunos casos, quizá muy acelerada en otros, en no pocos sin la debida reflexión y la necesaria formación, como tenía que ser, pues muchas de las intervenciones lo fueron de urgencia y otras de necesidad. Pero es cierto que muchos monumentos y edificios históricos como centros urbanos tradicionales de valor estético importante sufrieron restauraciones o rehabilitaciones muy agresivas, no pocas veces violentas y destructoras, las más de las veces forzando sus usos. Pero junto a ello se ha podido discurrir a un momento presente más pausado, de mayor prudencia. En parte por los abusos cometidos, otra posibilidad porque la mayoría de los grandes contenedores ya están ocupados, quizá también por que la sociedad ha controlado mejor los movimientos especulativos al asumir todos valores ya explícitos para el común.

Todo ello nos permite replantear el papel tanto de la sociedad como de los centros públicos y privados dedicados a la protección y conservación del patrimonio.

En esta situación jugó un papel muy importante en la creación de métodos, en el conocimiento de técnicas y en la formulación de criterios el Instituto Central de Restauración de Madrid. Hace unos años Isabel Cabrera-Kábana, su directora, invitó a un grupo de estudiosos del Patrimonio a participar en unas jornadas allí celebradas. Entre los asistentes estaban Román Fernández-Baca, Ángel Viñas, Alberto Humanes, Antoni González y otros más. En una mesa redonda personalmente recordé los extraordinarios profesionales con que cuenta, que recogen una tradición larga en la historia de la restauración de bienes muebles e inmuebles en nuestro país y que su labor y trabajo se actualizaba constantemente como demostraban sus intervenciones. Recordé algunos datos históricos del ICROA, en aquél momento IPHE, como que este organismo que se fundara en año 1961, que se reformara en el año 65, que conoció épocas de esplendor como la de Dionisio Hernández Gil, Felipe Vicente Garín, etc., en determinado momento, después de que se traspasaran las competencias de patrimonio a las Comunidades Autónomas parecía haberse ausentado deliberadamente del debate contemporáneo de la restauración en España. No en el sentido de su capacidad profesional o de la presencia en los foros de sus integrantes a título individual, que evidentemente seguían siendo de primera magnitud, sino en el plano de la influencia y transferencia en los medios especializados y en los ámbitos de este campo técnico y científico. Recordaba, y criticaba negativamente, que había desaparecido su presupuesto para publicacio- 

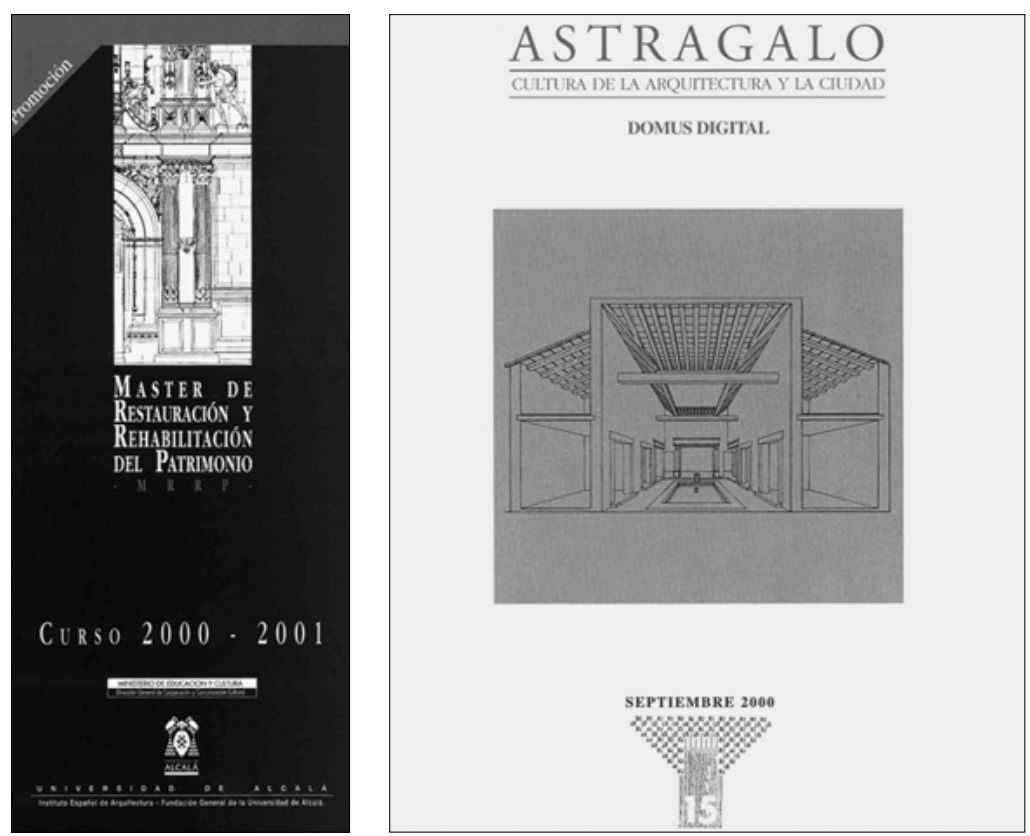

nes y que sin este vehículo mal se podía ejercer una influencia en cualquier sector y menos hacer ver la intensa labor que allí se hacía.

Esta situación -no sé si forzada por motivaciones políticas de no interferir en las Comunidades Autónomas- entendía yo, y sigo creyéndolo, era negativo para España y para todos sus ciudadanos, porque al margen de lo que puedan querer las naciones y los pueblos españoles, a los que nadie impide destinar los esfuerzos que deseen para estudiar y conservar el patrimonio (todo lo contrario, ojalá los multiplicaran) era un paso atrás. Pues todo lo que el IPHE había avanzado en 25 años en ideología, en el debate, en los criterios, en descubrimientos de nuevas tecnologías y métodos del patrimonio, no se transferían a la sociedad ante su silencio oficial.

Entiendo que, sin menoscabo de otros centros regionales que podrían o no secundarlo, el IPHE debería ser el dirigente, el faro que orientase en España y hacia fuera sobre los antiguos y los nuevos problemas del patrimonio español, porque posee un cuadro muy cualificado de profesionales, unos magníicos laboratorios y una larga experiencia. Este discurso ha llevado a que sea por camino directo (no existen esas directrices), o precisamente por el inverso (habrá que crearlas en otros lugares), por lo que las Comunidades se han visto en la obligación de ir creando sus propios centros para ocupar precisamente este papel, en muchos casos reiterando trabajos, investigaciones y procesos ya años superados por el IPHE. Y esto no es serio socialmente, porque el dinero de unos y de otros es público y hay que responder de él. Las Comunidades Autónomas, según la Ley de Patrimonio de 1985 -y a través de sus propios marcos jurídicos al respecto después desarrollados- tienen las competencias y el derecho a crear los centros que estimen necesarios. En parte la laguna que hemos señalado ha motivado la aparición de algunos de ellos o el proyecto de creación de otros.
Y este ha sido el caso de la Autonomía andaluza, la primera en crear en España su propia ley de patrimonio y la primera en establecer un centro para su estudio y su tratamiento: el IAPH, que en apenas unos pocos años se ha convertido ya en referencia obligada por sus aportaciones, no sólo en los campos de la formación, en la práctica directa, sino incluso en la publicación a través de sus colecciones de libros y de su revista $\mathrm{PH}$ conocimientos que todos anhelamos.

En igual sentido, pero dirigido específicamente hacia los bienes inmuebles hay que destacar el ejemplo del Servicio de Patrimonio Arquitectónico Local de la Diputación de Barcelona, del que no voy a tratar, pues, precisamente por sus publicaciones y por su prestigio nacional e internacional no es necesario, además de por que su director, el arquitecto Antoni González, participa también en estas jornadas y él expresará su labor mejor que yo.

Releyendo las declaraciones de la organización del IP$\mathrm{HE}$, y el último decreto de transformación de sus funciones, me interesa destacar que allí se señala como competencias y misiones a realizar la elaboración de planes para la restauración y conservación del patrimonio histórico español, el estudio de métodos y técnicas actualizadas para la restauración y conservación del mismo, el archivo y sistematización de los trabajos realizados en cada caso concreto, la formación de técnicos y especialistas que atiendan estos fines del instituto, así como la propuesta del establecimiento, en su caso, de convenios con otras administraciones públicas y entidades públicas o privadas necesarias para el desarrollo de sus funciones específicas.

Muchos de estos aspectos, si se realizan, no llegan a conocimiento de los especialistas ni de los ciudadanos.

Cuando hace unos meses visité el Laboratorio de Investigación de Monumentos Históricos en Francia (L.R.M.H.), con un grupo de colegas y estudiantes de restauración de Valladolid, nos sorprendimos gratamente, pues en un gran armario estaban expuestas todas las publicaciones e investigaciones sobre patrimonio que habían producido, y todas eran accesibles al público interesado. Igual ocurre con la producción del Servicio de Patrimonio Arquitectónico Local de Barcelona, que tiene la sana y obligada costumbre de publicar todas sus intervenciones y experiencias, material de un valor incalculable para todos los profesionales.

Lo mismo podemos decir del IAPH. Su excelente Boletín de Patrimonio Histórico (PH), los Cuadernos del Instituto Andaluz de Patrimonio, la producción de sus restauraciones, sus aportaciones en bienes muebles, sus catalogaciones, etc., verdaderamente son excepcionales.

La revista es conocida en numerosos países, y ello, lógicamente nos llena de orgullo cuando en París, Roma, Lisboa, Santa Fe de Bogotá o México nos hablan de la labor de PH, ya con más de 12 años de existencia y unos contenidos serios y rigurosos. Todos los documentos internacionales de conservación aconsejan a 
los gobiernos y a las administraciones crear medios de difusión de sus experiencias para aprovecharlas todos los profesionales. Son muy conocidas las revistas de la Getty, del Ministerio francés, de ICOMOS, de muchas entidades e instituciones en Italia, en Gran Bretaña, en Portugal o incluso en países de la América hispana. Sin embargo en España esta recomendación solo conoce el fracaso. Desde que en 1844 se declaró el primer Monumento Nacional español (la Catedral de León), han pasado muchos años, más de un siglo para tener bibliografía constante, continua sobre las intervenciones en nuestros monumentos, salvo actuaciones esporádicas. En la transición se reavivó la necesidad de disponer medios de fomento, divulgación o explicación de restauraciones y nació Koiné y otras revistas que pronto desaparecieron. Pervive el boletín de Hispania Nostra con noticias de interés y se ha creado Arete, ambas, como el boletín de Archival y otras pertenecientes a entidades privadas, lo cuál es verdaderamente elogiable. En el ámbito de la restauración arquitectónica hoy en España solo existen tres revistas, salvo otras coyunturales o de información sectorial (como la Clar, empresa de restauración).

De éstas que tienen alcance nacional $\mathrm{O}$, incluso internacional, una pertenece a América lbérica, S.A., Restauración\&Rehabilitación. Se trata de una revista comercial a la que hay que concederle un gran mérito puesto que ha acercado a una masa de veintitantos mil compradores estos temas. Su razón comercial le lleva a difundir entre sus asuntos artículos financiados por administraciones y entidades, con lo cual difunde también programaciones de carácter socio- político, lo que es absolutamente legítimo. Pero, además, por su variedad y por las diversas firmas que en ella colaboran se ha convertido ya en una fuente inexcusable. Otra revista es Loggia, de la Universidad Politécnica de Valencia que cuenta con apoyo de la Comunidad Autónoma Valenciana. Paga, lógicamente, el tributo de publicar temas regionales, pero es una revista profunda, seria como académica, y también con firmas de constatado prestigio. Como crítica personal se aprecia en ella una orientación sectorial en cuanto a la tendencia que recoge, quizá la más "moderna" sin contrapunto ni entrada a otras posiciones. Cierto que esto le otorga determinada personalidad.

Y dentro de esta tríada, tenemos la tercera revista, la más veterana, que es el Boletín PH del IAPH, esto es, financiada con fondos de la administración regional. Yo no conozco los intersticios andaluces; no sé si hay censuras respecto a los colaboradores de la misma, no sé si los artículos se seleccionan de alguna manera que no sea la científica, pero es innegable que sus contenidos son extraordinariamente rigurosos, que no aparecen reportajes de alharaca ni de exaltación de poderes. Sus aportaciones son verídicas investigaciones de primera mano, en muchos casos verdadera doctrina para responder a los problemas del patrimonio, específicamente del andaluz, pero por extensión del de España y de otros países. Junto a ello, las secciones de información sobre congresos, reuniones científicas, enlaces para intercambio de conocimientos, etc., son únicas en nuestro panorama.

\section{¿Cuál es el futuro de los institutos?}

La experiencia del IAPH se revela como una entidad absolutamente necesaria en el futuro. Otros que existen en España, desgraciadamente, no han pasado de convertirse en meros servidores técnicos para realizar cualquier restauración de bienes muebles, actividad que por otra parte arremete a la iniciativa privada en una sociedad privatizadora y economicista como la nuestra, por lo que su presencia y actividades son sobre todo desleales, impiden la generación de empleo especializado y la libre competencia. Para eso, en mi opinión, no hacen falta los Institutos ni otros centros similares en el sistema español, pues ya las correspondientes direcciones generales de patrimonio poseen sus técnicos cualificados para cumplir las misiones de control que le otorga la ley. Otra cosa sería que nuestro modelo variara hacia el italiano o el francés, siendo las superintendencias (las delegaciones de patrimonio) las encargadas de realizar las restauraciones más significativas. En nuestra situación es duplicar funcionarios y crear ámbitos de conflicto innecesario. Esto no quiere decir que no deban existir en España gabinetes de restauración oficiales de alta cualificación quienes serían los que se ocuparían de los temas verdaderamente delicados que no se podrían dejar al sector privado mientras este no alcance las cotas de calidad exigidas. Es como si estos institutos también crearan talleres de proyectos y empresas de restauración, aspiración la primera, que se pudo realizar a tiempo en España, pero que ahora parece desaconsejable. Las restauraciones realizadas por concurso público fallan en el sistema de inspección para verificar la ejecución pertinente y valorar los reformados. También por culpa de la aplicación de la Ley de Contratos del Estado, que aplican a las obras en los monumentos iguales criterios que a la obra nueva y que llevan en muchos casos a provocar las bajas excesivas y las subcontrataciones a empresas no especializadas.

La misión de los institutos, además de contar con los mejores profesionales de la sociedad, es estar en la vanguardia del patrimonio y ser el celo extremo del cumplimiento de la sensatez. Duplicidad difícil de conjugar, pero factible y que realizan otras entidades fuera de España que arriba se han citado. Además su futuro está relacionado con el del propio patrimonio, en el sentido de que deben ser entes capaces de ir abriendo caminos de identificación, de conseguir sensibilizar a la opinión pública y a las administraciones sobre lo que hay que clasificar, de incidir en la reforma continuada de las leyes de protección y de conservación, pues los institutos deben realizar investigaciones punta y recoger las innovaciones tecnológicas y metodológicas que desarrollan otros entes - universidades, empresas, etc.- y por medio de sus instrumentos de mayor capacidad y agilidad operativa administrativa llevarlos a la práctica. Desde esta posición serán los más preparados para conseguir la evolución individual en la captación de los criterios más sensatos a partir del dominio del oficio y del pensamiento contemporáneo. Para todo ello, lógicamente, con los medios financieros necesarios y la dirección adecuada. 
La respuesta de los institutos oficiales debe ser pionera en la captación de los nuevos conceptos de patrimonio para involucrarse en su tutela. Mencionábamos antes cómo en los últimos veinte años se ha producido una explosión expansionista en la consideración de lo que es su significado, que ha arrasado con creces el concepto tradicional. Las previsiones para los próximos años, parecen que van a multiplicar esta identificación e inclusión de nuevos objetos y de nuevas ideas, que van a procurar grandes transformaciones en la sociedad y en la valoración de lo que fue del ayer con respecto a su rescate del olvido. Como ejemplo, yo refiero con frecuencia a mis alumnos, que en 1956 un dibujante prácticamente desconocido, Manuel Prieto, sacaba de su cabeza el diseño del Toro de Osborne, una silueta publicitaria con la marca de estos productos y en un contexto en el que en España esto no era diseño, ni se tenía más conciencia que la comercial, y muy limitada dada la situación en que se encontraba el país. La imagen tuvo fortuna y se multiplicó por nuestras carreteras como simple valla publicitaria. Les cuento cómo ya en los años noventa la alarmante siniestralidad de las carreteras llevó al Ministerio de Obras Públicas a prohibir mediante Ley toda publicidad en las mismas para evitar distraer a los conductores y eliminar ciertos riesgos comprobados de falta de atención. La reacción de diferentes sectores sociales, culturales e, incluso populares, se levantó no contra la medida ministerial que todos aceptaron como sensata y acertada, sino contra la desaparición de los toros que habían penetrado en la conciencia y en el acervo común. Su defensa a ultranza obligó, caso insólito, a que en 1997, el Tribunal Supremo concediera la salvación de estos objetos publicitarios presentando, como valor prioritario el simbólico y material, el signo, ordenando eliminar la referencia comercial. Les cuento también que hoy cuando se viaja por Méjico aparecen algunos toros en diferentes partes de esta nación, que también se ve alguno en el sur de Francia. Que ya no sólo los andaluces, o los españoles, sino más allá se han convertido en un objeto patrimonial universal. Una tablas de madera o chapa, y una silueta pintadas de negro, se han convertido en un referente valioso, en un objeto de identidad, en un objeto de representación, se han convertido en la herencia de nuestros padres, unos padres cercanos, unos padres próximos y se han introducido ya en acervo cultural de todos nosotros.

El suceso referido representa un modelo simple de cómo algo físico sin ningún valor material, sin caracteres de antigüedad ni de documento histórico, por su belleza estética y capacidad de comunicación ha conseguido penetrar en esos nuevos conceptos patrimoniales lleno de significados expresivos.

Otro factor que creo va a ser revolucionario en las próximas décadas es lo que denomino el laicismo de toda clase de patrimonio, en el sentido de su utilización civil, preponderancia terrenal y secularizada, sin que ello suponga renunciar a sus valores espirituales, pues los consumidores del mismo lo son, en la mayoría de los casos, por razones de estética y no de creencias. Es la sociedad civil, al margen de las tendencias religiosas y político-ideológicas, quien se compromete como cuerpo social entero en la conservación de la herencia del pasado, sea de origen y uso religioso o no. Y ello por los movimientos universalistas de la propiedad del patrimonio y por la propia necesidad de las religiones para conservar su cuantioso legado. En España la Iglesia Católica se ve incapaz de atenderlo, no sólo por razones económicas, sino también demográficas, funcionales, etc., etc. Todos vemos como se hunden los edificios a causa de la despoblación, pronto veremos cómo desaparecen comunidades conventuales y monacales por simple consunción de los miembros de estas órdenes. Vemos cómo se abandonan al uso litúrgico templos e iglesias en poblaciones en las que surgieron en otro contexto de religiosidad que hoy no existe convirtiendo en obsoletas estas construcciones, como ocurre con las fábricas de la revolución industrial, o como ha ocurrido con cantidades ingentes de arquitectura popular o con casi toda la arquitectura preindustrial. A la ruina y el abandono sólo se le puede responder con la reutilización para nuevas funciones, muchas veces muy alejadas de las que provocaron el nacimiento de todas estas edificaciones. Pero no existe otra solución, además de vernos obligados a realizar una rigurosa selección de lo mejor y a crear los mecanismos de gestión para que pueda generarse nuevos medios de conservación de esta cada vez más inmensa herencia. Otra labor -esta vez ingrata- de los Institutos para concienciar a la sociedad sobre los criterios y los mecanismos de salvaguarda de la memoria, eligiendo cruelmente lo que es urgente, lo que puede resistir a medio plazo y catalogando y archivando elementos gráficos y documentales de lo que irremisiblemente va a desaparecer. Se trata en definitiva de ser capaces de generar recursos y los que existen saber distribuirlos de la mejor manera; programa que deben realizar los técnicos y no los políticos.

El patrimonio, a pesar de la titularidad, es por su propia esencia colectivo, es un objeto propiedad no solo de quien lo usa sino de quien lo mantiene, quien lo conserva, quien convive con él, quien todos los días se siente responsable de su existencia y de su continuidad. La laicización provocará una multipropiedad que deberá trasladarse a nuestras leyes para compartir la responsabilidad, más allá de los actuales mandatos de la obligatoriedad del titular como directo sujeto de la tutela, y más explícita la subrogación de las administraciones y con más poderes ejecutivos y más contraprestaciones si aquél no cumple con sus deberes, sea una Iglesia, un privado, una institución o una entidad.

Los Institutos de Patrimonio, y en este caso querría señalar alguna objeción a los planteamientos actuales de muchos de ellos, no deben ser meras oficinas de burocracia informativa o simples talleres de ejecución de algunas actividades, deben ser creadores de nuevas capacidades de gestión y de intervención. La Carta del Riesgo elaborada por el Instituto Central del Restauro de Roma marca todo un programa de actuación al margen de las instituciones políticas que debe recoger el reto y darle soluciones. 
Me preocupa mucho también otro suceso negativo de nuestro patrimonio al que debería intentar ponérsele remedio. Se trata de eliminar lo que creo es una lacra que conserva la legislación española y han copiado las autonómicas heredada del pasado, ya un tanto remota, pues viene desde la guerra civil. Pienso que una de las mayores tragedias del patrimonio español actual es que continúen teniendo responsabilidad las consejerías de Fomento o de Obras Públicas sobre parte de aquel legado inmueble del pasado (arquitecturas, ciudades, paisajes), donde no se aplican criterios, o al menos no los suficientes, para su conservación, donde las restauraciones siempre se realizan con ideas de modernización, de utilización sin la valoración necesaria de la preexistencia. Animaría a las administraciones españolas y a las de las comunidades autónomas a copiar el modelo francés, a seguir la valentía de François Barre desgajando ese sector de los Ministerios de Obras Públicas y trasladándolo a Patrimonio, pues es a quién debe pertenecer. Esta división nuestra de que es competencia de Cultura los Bienes de Interés Cultural que están declarados y del otro ministerio el patrimonio que no lo está, es verdaderamente absurda y no se sostiene bajo ningún argumento, ni aunque se defienda que éste último posee más medios económicos, pues no es tan complejo redistribuirlos.

El Instituto Andaluz de Patrimonio es un modelo ejemplar de los que existen en España. Vanguardista y pionero, comprometido, referencia para demostrar a los de fuera que aquí también se trabaja y se avanza. Pero también quiero ponerle un reparo, exponerle una demanda de muchos a un problema que debería intentar subsanar, junto con la sociedad andaluza que le apoya, el de su incursión más valiente, más segura, en el ámbito de la conservación de los bienes inmuebles, de los núcleos urbanos, en el mundo de la arquitectura, los edificios, los monumentos, el territorio, en el debate contemporáneo del proyecto de conservación y restauración, en el que esperamos también sus aportaciones teórica y prácticas, aunque entre en colisión con otros organismos o entidades. En este campo en España existe una gran orfandad, pues sólo profesionales a título individual, desde las universidades o desde otras entidades, especialmente y muy destacable desde el Servicio de Patrimonio Arquitectónico Local de la Diputación de Barcelona se produce ese necesario clima de investigación y discusión.

Finalmente me gustaría destacar de las muchas virtudes del IAPH, como directriz para otros institutos, su capacidad organizativa y su eficiencia a través de las distintas secciones en que se ha articulado, como las de documentación, intervención, formación, arqueología subacuática, así como la de Investigación más Desarrollo (I+D). A este respecto recordaba arriba que en los Programas Rafael de la Unión Europea cuyos proyectos se habían otorgado este ejercicio no aparecían propuestas españolas, excepto tres del IAPH y una de nuestro Instituto de Valladolid. Precisamente en ese ámbito de la investigación es donde el IAPH, en mi opinión, está ofreciendo sus más gra- nados frutos generando avances que, quizá, no son valorados directa o inmediatamente por los andaluces, por la sociedad en general. Le pediría que no renunciara a estos esfuerzos, a este factor oscuro, solitario, que no consigue expresión ni relumbre en los medios de prensa, que no sale en los titulares de las noticias televisivas, pero gracias a los cuales se está realizando una extraordinaria aportación, que sí emana en sus Boletines, en sus Cuadernos y publicaciones, en sus Másters y Cursos, en la formación de una nueva generación de expertos, que son el reflejo y la transferencia de esos conocimientos en la mejor capacitación de sus equipos. Y esto es crear doctrina que beneficia a todos.

El Instituto también debe tender a extender la Cultura del mantenimiento del Patrimonio, un factor que no acaba de integrarse en nuestra sociedad (a pesar o contra la reciente LOE), que no consigue impregnar a los organismos de las administraciones públicas tanto centrales como regionales o locales, que han olvidado muchos titulares de objetos patrimoniales, propietarios civiles y la Iglesia Católica. Este fenómeno que se desgaja siempre de la responsabilidad de la realización de la conservación y de la restauración, en el cual los técnicos, por culpa de la legislación, se lavan las manos; en el cual las propias administraciones, por razón de los ciclos políticos y de los cambios de partidos y de grupos, tampoco quieren asumir excesivas responsabilidades; sin olvidar a los propietarios de los BIC, que esperan siempre la subvención constante para restaurar, cuando conservar evitaría estas onerosas actuaciones realizadas con dineros públicos. Necesitamos mejorar la inspección, y si las direcciones generales de patrimonio no son eficaces en esta instrumentación ésta deberá confiarse también a los Institutos. Como recomienda la "Carta de Cracovia 2000", exijamos los proyectos de obra concluida, los planes de mantenimiento de los edificios restaurados, creemos la cultura de la continuidad, acostumbremos a la responsabilidad de la vigilancia del buen uso del dinero público que incansablemente se destina a los monumentos una y otra vez por falta de cuidado y de simple atención a pequeños problemas que generan, de no sustanciarlos, grandes inversiones negativas para todos. La sociedad también tiene un límite en este sentido, será generosa si los monumentos representan su identidad, estará satisfecha y hará sacrificios personales y colectivos si aprecia que genera valores culturales y recursos sociales y económicos, pero no soportará, si nuestro entorno cada día avanza más en la democracia y en la transparencia de la gestión, si se demuestra que se produce el derroche a su costa.

Me resta felicitar al IAPH y a todos sus miembros por la fructífera labor realizada en esta década que ha pasado y desearles a todos que cumplan muchos años más en favor de nuestro patrimonio. Desearles que sigan trabajando sin olvidar nunca, como lo ha hecho hasta ahora, que éste es un instrumento fundamental para conseguir el desarrollo sostenible de este pueblo. 